\title{
A Direct Algorithm for Estimating Land Surface Broadband Albedos From MODIS Imagery
}

\author{
Shunlin Liang, Senior Member, IEEE
}

\begin{abstract}
Land surface albedo is a critical variable needed in land surface modeling. The conventional methods for estimating broadband albedos rely on a series of steps in the processing chain, including atmospheric correction, surface angular modeling, and narrowband-to-broadband albedo conversions. Unfortunately, errors associated with each procedure may be accumulated and significantly impact the accuracy of the final albedo products. In an earlier study, we developed a new direct procedure that links the top-of-atmosphere spectral albedos with land surface broadband albedos without performing atmospheric correction and other processes. In this paper, this method is further improved in several aspects and implemented using actual Moderate Resolution Imaging Spectroradiometer (MODIS) imagery. Several case studies indicated that this new method can predict land surface broadband albedos very accurately and eliminate aerosol effects effectively. It is very promising for global applications and is particularly suitable for nonvegetated land surfaces. Note that a Lambertian surface has been assumed in the radiative transfer simulation in this paper as a first-order approximation; this assumption can be easily removed as long as a global bidirectional reflectance distribution function climatology is available.
\end{abstract}

Index Terms-Broadband albedo, land surface, MODIS, multispectral imagery, remote sensing.

\section{INTRODUCTION}

$\mathbf{L}$ AND SURFACE broadband albedo is a fundamental component in determining the earth's climate. It is a parameter needed by both global and regional climatic models and for computing the surface energy balance. The seasonal and long-term vegetation dynamics that significantly impact the climate are reflected by the dramatic variations of albedo. According to Hartmann et al. [1], the surface absorbs about twice as much solar radiation as does the atmospheric column (160 versus $79 \mathrm{Wm}^{2}$ ). Surface solar absorption is modulated by the surface shortwave albedo.

Although many algorithms for estimating land surface albedos have been proposed [2], most work mainly by focusing on spectral (or narrowband) albedos. Additionally, no global broadband albedo products of land surface had been operationally produced until the Moderate Resolution Imaging Spectroradiometer (MODIS), one of the sensors in the National Aeronautics and Space Administration (NASA) Earth Observing System (EOS) Terra platform, launched in 1999. MODIS provides comprehensive and frequent global

Manuscript received July 13, 2001; revised October 3, 2002. This work was supported in part by the National Aeronautics and Space Administration (NASA) under Grant NAG5-6459.

The author is with the Department of Geography, University of Maryland, College Park, MD 20742 USA (e-mail: sliang@geog.umd.edu).

Digital Object Identifier 10.1109/TGRS.2002.807751 earth imaging in 36 spectral bands and at variable spatial resolutions. For land applications, the first seven spectral bands are primarily used, and their spectral and spatial characteristics are listed in Table I. The swath width of MODIS is $2300 \mathrm{~km}$, with the across-track field-of-view angle of $110^{\circ}$. MODIS images the earth on a two-day repeat cycle, with a one-day or more frequent repeat at higher latitudes greater than $30^{\circ}$ due to orbital convergence.

The MODIS land surface products are derived through a series of steps in the processing chain [3], [4] as illustrated in Fig. 1, including atmospheric correction [5], angular modeling for calculating spectral (narrowband) albedos [6], and narrowband-to-broadband albedo conversions [7]. The accuracy of the MODIS albedo products depend on the performance of all these processes. Errors associated with each procedure may be canceled out, but are also very likely to accumulate. For example, the MODIS atmospheric correction algorithm [5] requires the aerosol product [8]. Determining the aerosol optical depth over land is based on the "dark-object" approach that relies on the existence of dense vegetation canopies widely distributed over the scene [8]. The "dark-object" method does not work well over the nonvegetated surfaces (e.g., snow, ice, desert, and winter landscape in the northern hemisphere) [9], but nonvegetated surfaces have larger albedos and thus greater feedback to the atmosphere. "Until EOS determines the surface albedo of all land surfaces to greater accuracy, we cannot adequately quantify the radiative forcing to climate that is associated with changes in land use" [1].

An alternative scheme developed in our earlier study links TOA (top-of-atmosphere) narrowband albedos with three land surface broadband albedos using a feedforward neural network (NN) without performing any atmospheric corrections [10]. This idea stems from earlier studies [11]-[14] that linearly related TOA and surface broadband albedos. Surface broadband albedo depends on surface spectral reflectance as well as atmospheric conditions. TOA observations contain information on both surface reflectance and atmospheric optical properties, which implies that it is possible for us to predict the broadband albedos using TOA narrowband albedos without performing any atmospheric corrections.

Those earlier studies mainly focus on the linkage of planetary shortwave albedo with surface shortwave albedo. In our earlier study [10], we suggested linking several TOA spectral albedos with surface broadband albedos. In this study, the major objective is to implement this idea by using actual MODIS observations. However, several aspects of this algorithm have been significantly improved. Section II outlines this new algorithm. Attention will be paid to the improvements over our previously 
TABLE I

First Few MODIS BAND SPECTRAL RANGES AND SPATIAL RESOlUtions

\begin{tabular}{c|c|c|c|c|c|c|r}
\hline & 1 & 2 & 3 & 4 & 5 & 6 & 7 \\
\hline spectral $(\mathrm{nm})$ & $620-670$ & $841-876$ & $459-479$ & $545-565$ & $1230-1250$ & $1628-1652$ & $2105-2155$ \\
\hline spatial $(\mathrm{m})$ & 250 & 250 & 500 & 500 & 500 & 500 & 500 \\
\hline
\end{tabular}

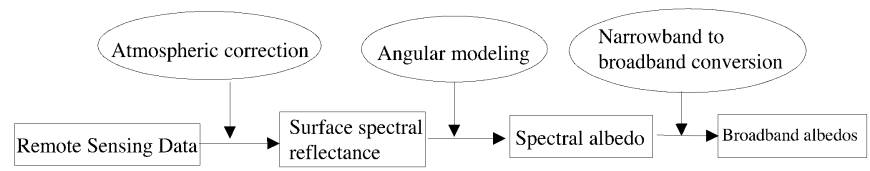

(a)

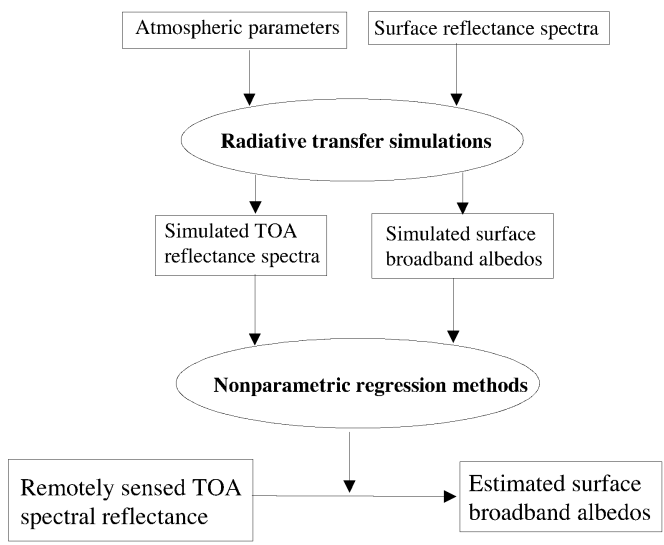

(b)

Fig. 1. Illustration of the procedures of (a) the current land surface broadband albedo mapping and (b) the proposed new method.

published algorithm [10]. Several cases studies will then be reported in Section III. The first case is to validate the accuracy of this algorithm. Several MODIS images over a remote sensing test site at Beltsville, MD were processed, and the derived surface broadband albedos were compared with ground measurements that were scaled through Landsat7 ETM+ imagery. The second case demonstrates how this new algorithm can automatically eliminate thick aerosol effects. A brief discussion and conclusion is given at the end of the paper.

Before proceeding, it is worth discussing the major differences between this method and the current MODIS algorithm [3], [4]. The current MODIS algorithm is based on physical understanding of all processes involved, and we are learning where and how to improve it as more data and knowledge are accumulated. It can be referred to as a physical approach. Our new method is mainly a statistical one using nonparametric regression, but it also incorporates physical principles through extensive radiative transfer simulations. It can be considered a hybrid approach. Although some assumptions (e.g., a Lambertian surface) are made in this study to simplify the process, this new method does not prevent from incorporating new physical understanding and accumulated knowledge.

\section{NEW METHOD}

The basic procedure is similar to that in our previous study [10], [29], which consists of two steps as illustrated in Fig. 1. The first step is to conduct extensive radiative transfer simulations using MODTRAN4 [15], and the second step is to link the simulated TOA reflectance with surface broadband albedos using nonparametric regression algorithms. This procedure, however, has been significantly improved in several aspects in this study. First, many more surface reflectance spectra of different cover types with different conditions have been incorporated into the radiative transfer simulations. In our previous study, only 20 spectra were considered. Second, an attempt has been made to estimate land surface broadband albedos using TOA reflectance, instead of TOA spectral albedos. This improvement has in fact greatly simplified this method, since calculating TOA spectral albedo requires TOA angular modeling that might introduce large errors. Lastly, the projection pursuit regression method has been also explored to link TOA directional reflectance with surface broadband albedos in conjunction with the NN method.

\section{A. Radiative Transfer Simulations}

For a given atmospheric and surface condition, we need to know the directional reflectance at the top of the atmosphere. Many radiative transfer packages are available right now for us to achieve that, such as MODTRAN [15], $6 \mathrm{~S}$ [16], and SBDART [17]. MODTRAN has been extensively used in our studies.

One of the major differences from our previous study [10] is that we ran MODTRAN without using measured surface reflectance spectra. Since the number of surface reflectance spectra was increased from 20 in the previous study to 256 , representing a variety of surface cover types and conditions, a novel approach is required to decouple surface reflectance spectra in the simulations. This decoupling approach can incorporate as many surface reflectance spectra as we want without increasing the simulation significantly. Specifically, MODTRAN was run three times with three surface reflectances $(0.0$, 0.5 , and 0.8 ) for each atmospheric condition and solar-viewing geometry. Assuming the surface is Lambertian, the downward flux $F\left(\mu_{i}\right)$ and upwelling radiance at the TOA $L\left(\mu_{i}, \mu_{v}\right)$ can be expressed by [18]

$$
\begin{gathered}
F\left(\mu_{i}\right)=F_{0}\left(\mu_{i}\right)+\frac{r_{s}}{1-r_{s} \bar{r}} \pi \mu_{i} E_{0} \gamma\left(\mu_{i}\right) \bar{r} \\
L\left(\mu_{i}, \mu_{v}\right)=L_{p}\left(\mu_{i}, \mu_{v}\right)+\frac{r_{s}}{1-r_{s} \bar{r}} \mu_{i} E_{0} \gamma\left(\mu_{i}\right) \gamma\left(\mu_{v}\right)
\end{gathered}
$$

where $\mu_{i}$ is the cosine of solar zenith angle $\left(\theta_{i}\right) ; \mu_{v}$ corresponds to the viewing zenith angle; $F_{0}$ and $L_{p}$ are the upwelling flux and path radiance without the surface contribution (i.e., surface reflectance is zero, $\left.r_{s}=0\right) ; \bar{r}$ is the spherical albedo of the atmosphere; $E_{0}$ is the TOA downward flux; and $\gamma\left(\mu_{i}\right)$ and $\gamma\left(\mu_{v}\right)$ are the total atmospheric transmittance of the solar illumination path and the viewing path, respectively. Results from three MODTRAN runs form six equations that enable us to determine these unknowns $\left(F_{0}, L_{p}, \bar{r}, \gamma\left(\mu_{i}\right)\right.$, and $\left.\gamma\left(\mu_{v}\right)\right)$ in the above equations. As long as these unknowns are determined, it 
is straightforward to calculate downward flux at the surface and TOA radiance with any surface reflectance spectra.

It is critical to use the representative surface reflectance spectra in data simulations. Different surface reflectance spectra from the U.S. Geological Survey's digital spectral library), from measurements by J. Salisbury at the Johns Hopkins University and from the Jet Propulsion Laboratory's spectral library were collected. Most of these spectra were measured in the laboratory. To account for the natural environment conditions, over 100 reflectance spectra of different surface cover types were extracted from the Airborne Visible-Infrared Imaging Spectrometer (AVIRIS) imagery, an airborne hyperspectral sensor. Depending on the spatial variations of surface reflectance, different window sizes were selected, and a median value was then calculated for each waveband. AVIRIS has 224 bands; unfortunately, we found 20 bands of little value because of noise or the absence of signals. Spectral reflectances $(0.25-2.5 \mu \mathrm{m})$ were interpolated from the remaining 204 bands. In total, we employed 256 surface reflectance spectra in this study, including soil (43), vegetation canopy (115), water (13), wetland and beach sand (4), snow and frost (27), urban (26), road (15), rock (4), and other cover types (9). They have different wavelength dependences and magnitudes, from coastal water (low albedos) to snow and frost (high visible albedos). It represents the most comprehensive surface reflectance spectra database we could assemble with available data. It will also be updated regularly as new measured data are available.

In the MODTRAN simulations, 11 atmospheric visibility values $(2,5,10,15,20,25,30,50,70,100$, and $150 \mathrm{~km})$ were used for different aerosol loadings, four aerosol models (rural, Navy maritime, urban, and troposphere), and five atmospheric profiles (tropical, mid-latitude winter, subarctic summer, subarctic winter, and US62) that also represent different water vapor and other gaseous amounts and profiles. The aerosol models and atmospheric profiles used are the defaults in MODTRAN. For the operational application of this method, more should perhaps be included to represent the variable atmospheric conditions.

Land surface broadband albedo is simply defined as the ratio of the surface upwelling flux $\left(F_{u}\right)$ to the downward flux $\left(F_{d}\right)$

$$
\alpha\left(\theta_{i}, \Lambda\right)=\frac{F_{u}\left(\theta_{i}, \Lambda\right)}{F_{d}\left(\theta_{i}, \Lambda\right)}=\frac{\int_{\Lambda} F_{d}\left(\theta_{i}, \Lambda\right) r(\lambda) d \lambda}{\int_{\Lambda} F_{d}\left(\theta_{i}, \Lambda\right) d \lambda}
$$

where $\Lambda$ is denoted to the waveband from wavelength $\lambda_{1}$ to wavelength $\lambda_{2} \Lambda \in\left(\lambda_{1}, \lambda_{2}\right)$. If $\Lambda \in(0.25,0.5 \mu \mathrm{m}), \alpha\left(\theta_{i}, \Lambda\right)$ is the total shortwave broadband albedo. The waverange $\Lambda \in$ $(0.4,0.7 \mu \mathrm{m})$ and $\Lambda \in(0.7,5.0 \mu \mathrm{m})$ correspond to visible and near-infrared (near-IR) albedos, respectively. $r(\lambda)$ is the surface spectral reflectance spectra.

The upwelling TOA radiance is further normalized to spectral reflectance

$$
R\left(\mu_{i}, \mu_{v}, \phi\right)=\frac{\pi L\left(\mu_{i}, \mu_{v}, \phi\right)}{\mu_{i} E_{0}}
$$

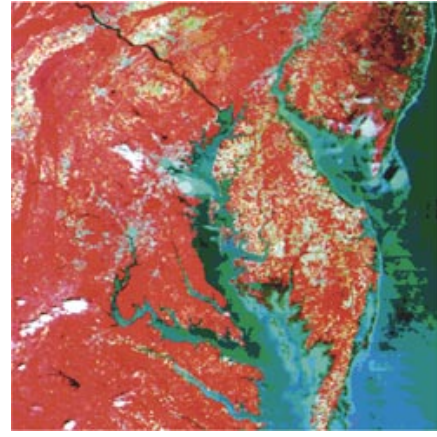

(a)

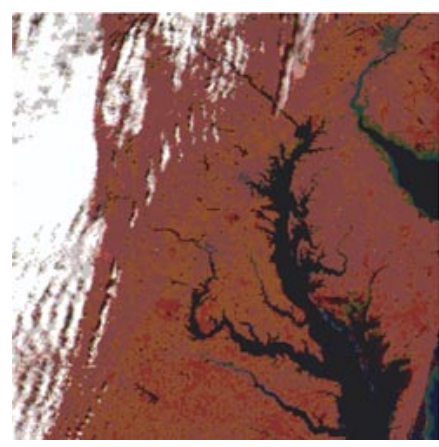

(c)

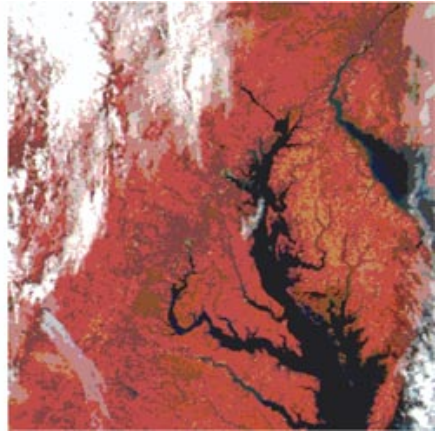

(b)

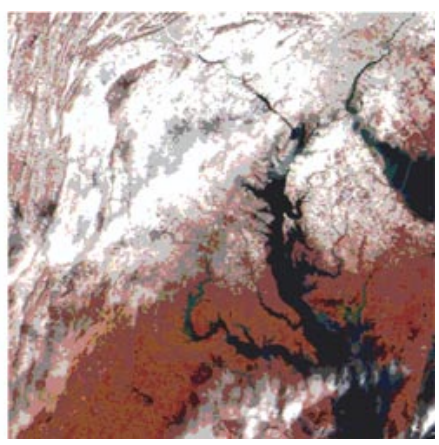

(d)
Fig. 2. MODIS imagery over the USDA Beltsville Agricultural Research Center validation site.

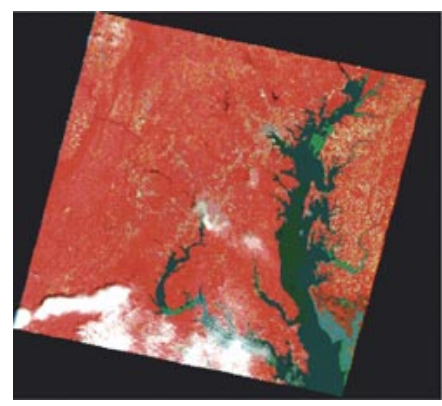

(a)

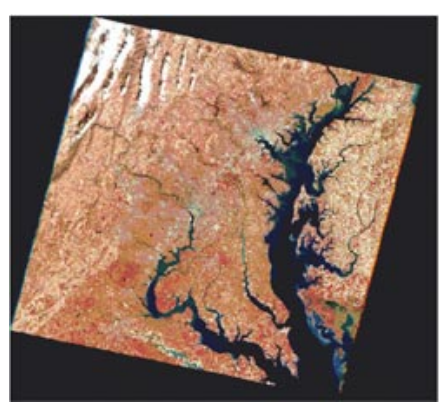

(c)

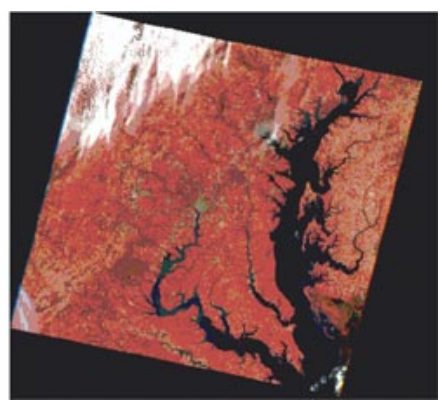

(b)

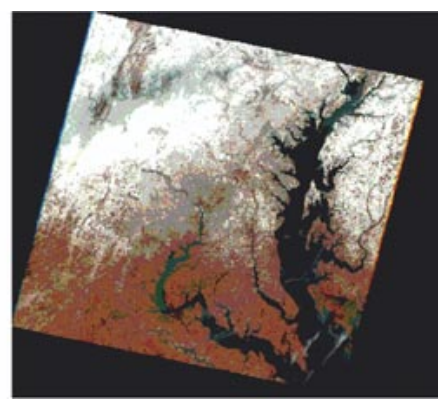

(d)
Fig. 3. ETM+ imagery over the USDA Beltsville Agricultural Research Center validation site.

The sensor spectral response functions $g_{i}(\lambda)$ can be integrated with these TOA reflectance spectra to generate the TOA reflectance of different spectral bands

$$
R_{i}=\frac{\int g_{i}(\lambda) R(\lambda) d \lambda}{\int g_{i}(\lambda) d \lambda} .
$$



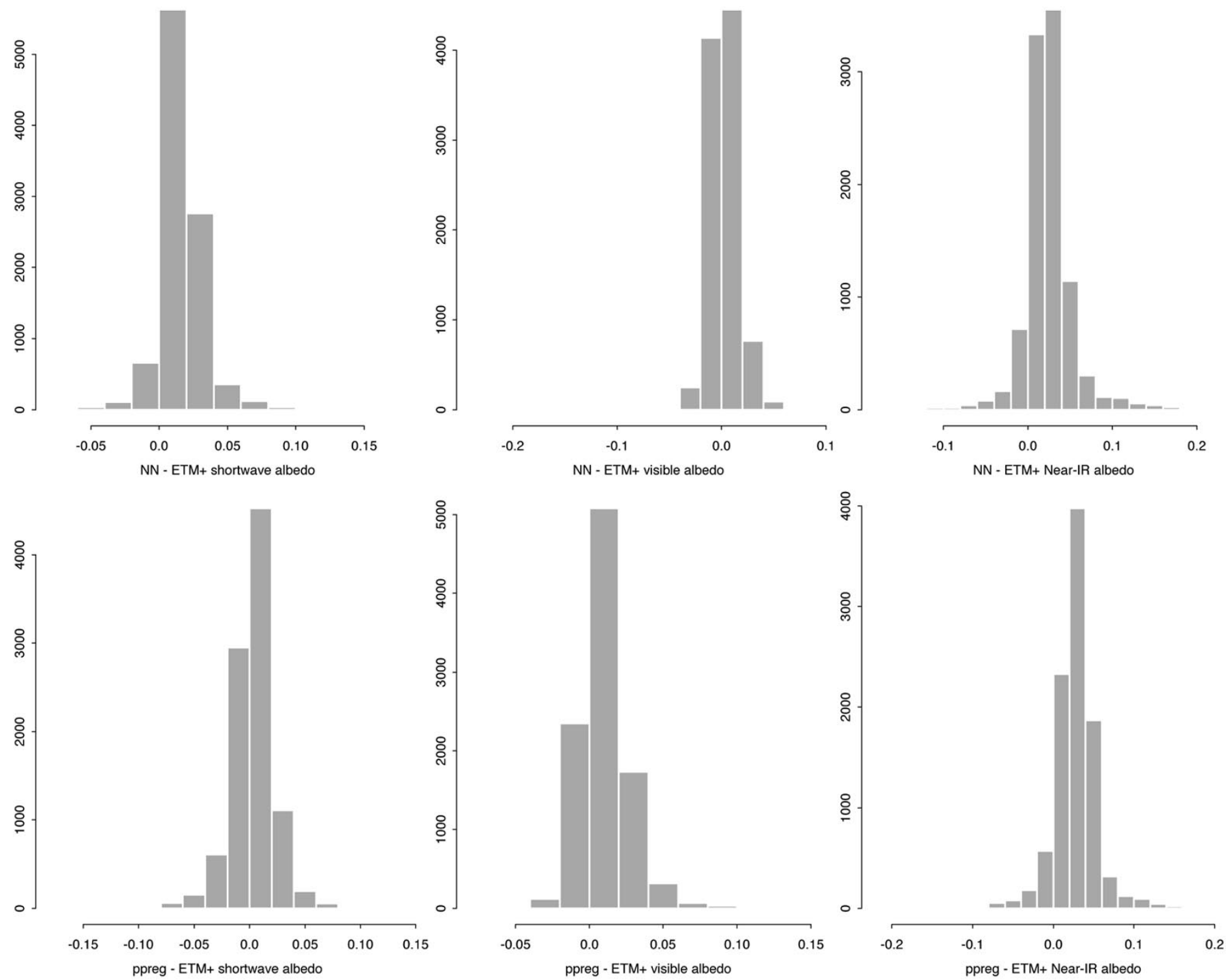

Fig. 4. Histograms of the three broadband albedo differences between those predicted by the NN method, projection pursuit regression (ppreg) method, and those converted from ETM+ imagery that was calibrated by the ground measurements. Both ETM+ and MODIS images were acquired on May 11, 2000.

TABLE II

ALBEDo DifFerENCES From THE ETM+ COMPUTED ALBEDOS

\begin{tabular}{c|c|c|c|c|c|c|c}
\hline Methods & Dates & \multicolumn{3}{|c|}{ Mean } & \multicolumn{3}{c}{ Standard Deviation } \\
\hline & & Shortwave & Visible & Near-IR & Shortwave & Visible & Near-IR \\
\hline \multirow{4}{*}{ nnet } & May 11, 2000 & 0.0165 & 0.0031 & 0.0243 & 0.0158 & 0.0131 & 0.0294 \\
\cline { 2 - 8 } & Nov. 3, 2000 & 0.0225 & 0.0182 & 0.0171 & 0.0333 & 0.0276 & 0.0476 \\
\cline { 2 - 8 } & Dec. 5, 2000 & 0.0385 & 0.0067 & 0.0653 & 0.0206 & 0.0109 & 0.0333 \\
\cline { 2 - 8 } & Jan. 22, 2001 & 0.0017 & -0.016 & 0.0140 & 0.0543 & 0.0636 & 0.0495 \\
\hline \multirow{4}{*}{ ppreg } & May 11, 2000 & 0.0029 & 0.0101 & 0.0276 & 0.0203 & 0.0166 & 0.0281 \\
\cline { 2 - 8 } & Nov. 3, 2000 & 0.0241 & 0.0193 & 0.0347 & 0.0322 & 0.0249 & 0.0471 \\
\cline { 2 - 8 } & Dec. 5, 2000 & 0.0316 & 0.0085 & 0.0654 & 0.0212 & 0.0112 & 0.0332 \\
\cline { 2 - 8 } & Jan. 22, 2001 & -0.0007 & -0.0144 & 0.0150 & 0.0553 & 0.0637 & 0.0483 \\
\hline
\end{tabular}

One of the major limitations in this simulation study is its assumption of Lambertian surfaces. The major reason is that we do not have a good understanding of the directional reflectance properties of various surface types at the MODIS resolution. Both MODIS and Multi-angle Imaging SpectroRadiometer (MISR) teams are producing global land surface bidirectional reflectance distribution function (BRDF) products [3], [19]. It will be straightforward to improve this procedure as long as we accumulate enough data, since many radiative transfer models have the capability to incorporate directional surface reflectance. However, it is speculated that the spectral dependence of surface reflectance spectra is the most important aspect.

\section{B. Statistical Algorithms}

As long as the database is created from the simulations described above, the next step is to link TOA reflectance to land surface broadband albedos. We proposed using an $\mathrm{NN}$ in our 

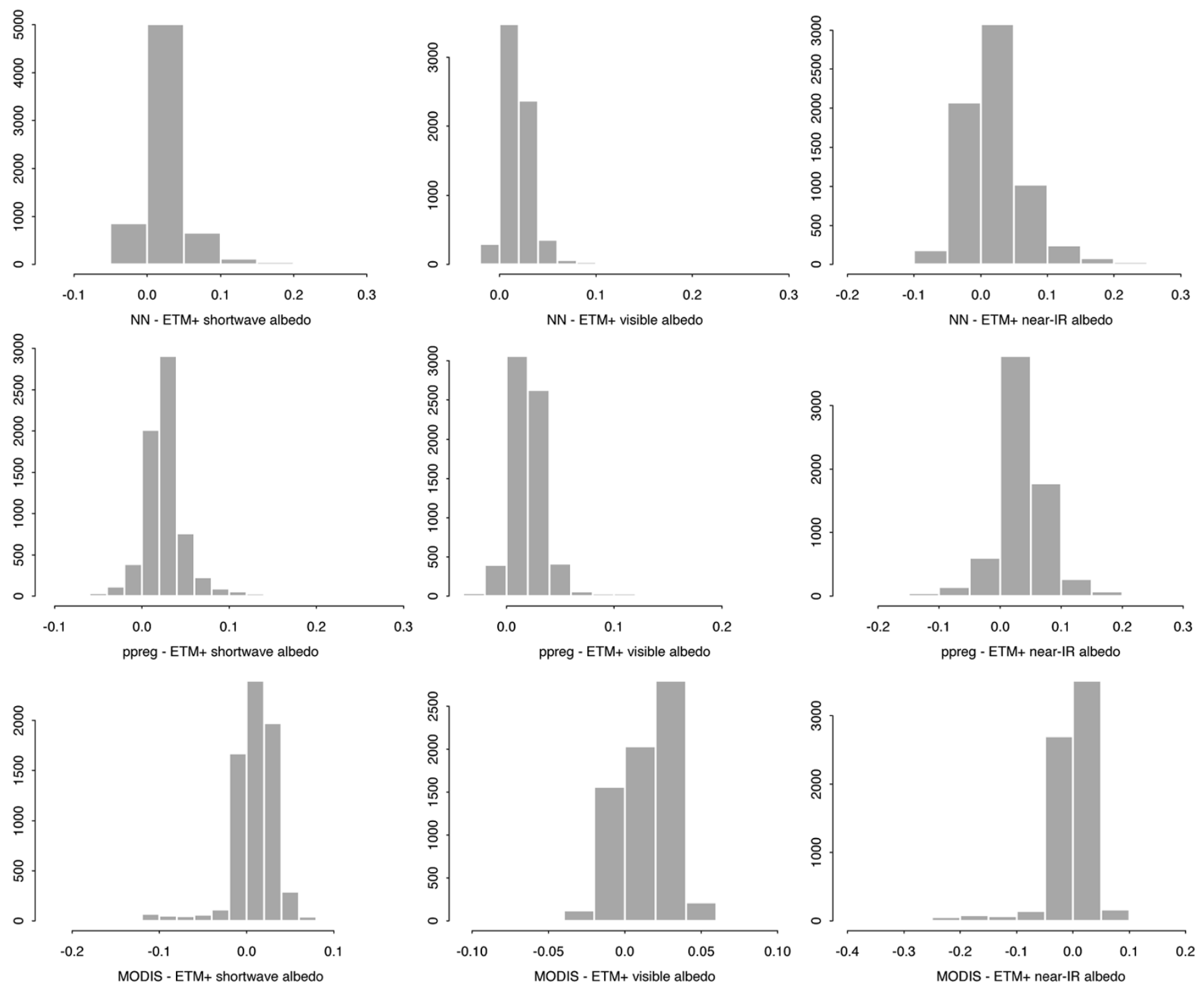

Fig. 5. Same as Fig. 3 except MODIS albedo products are also compared. Both ETM+ and MODIS were acquired on November 3, 2000.

previous study [10], but have also explored a new method called projection pursuit regression in this study. The general concept of this hybrid method is illustrated in Fig. 1(b).

1) Neural Network: Artificial neural networks (ANNs) can be seen as highly parallel dynamical systems consisting of multiple simple units that can perform transformations by means of their state response to their input information. The ANN approach has been used in different remote sensing applications [20], [21]. ANNs learn by example. In a typical scenario, an ANN is presented iteratively with a set of samples, known as the training set, from which the network can learn the values of its internal parameters.

There are at least four main aspects that should be considered in the application of ANNs:

1) preparing the training data from radiative transfer simulations;

2) designing the network architecture;

3) estimating the parameters, i.e., training a network;

4) assessing the performances of the network.
The key component is to design ANN architecture, which has a critical effect on the results. Various studies have shown that the NN's complexity-mainly the number of free parameters-must be fitted to the problem complexity and the number of available training samples. If the network is too complex, it will perfectly learn the training set (low bias), while generalizing very poorly (high variance). Controlling the complexity is, therefore, a necessity to ensure good generalization. It is a key issue when the training set is small, noisy, and partially inaccurate. However, our training dataset created from the radiative transfer simulation is huge and, therefore, is not a problem in this study.

The feedforward ANN used in this study has only one hidden layer (but we can decide the number of units in the hidden layer) and another free parameter (called the decay parameter). After extensive experiments, it is found that five hidden layers with the decay parameter $10^{-4}$ provide satisfactory results in all cases. The details on this $S$-plus function can be found in the literature [22], [23]. 

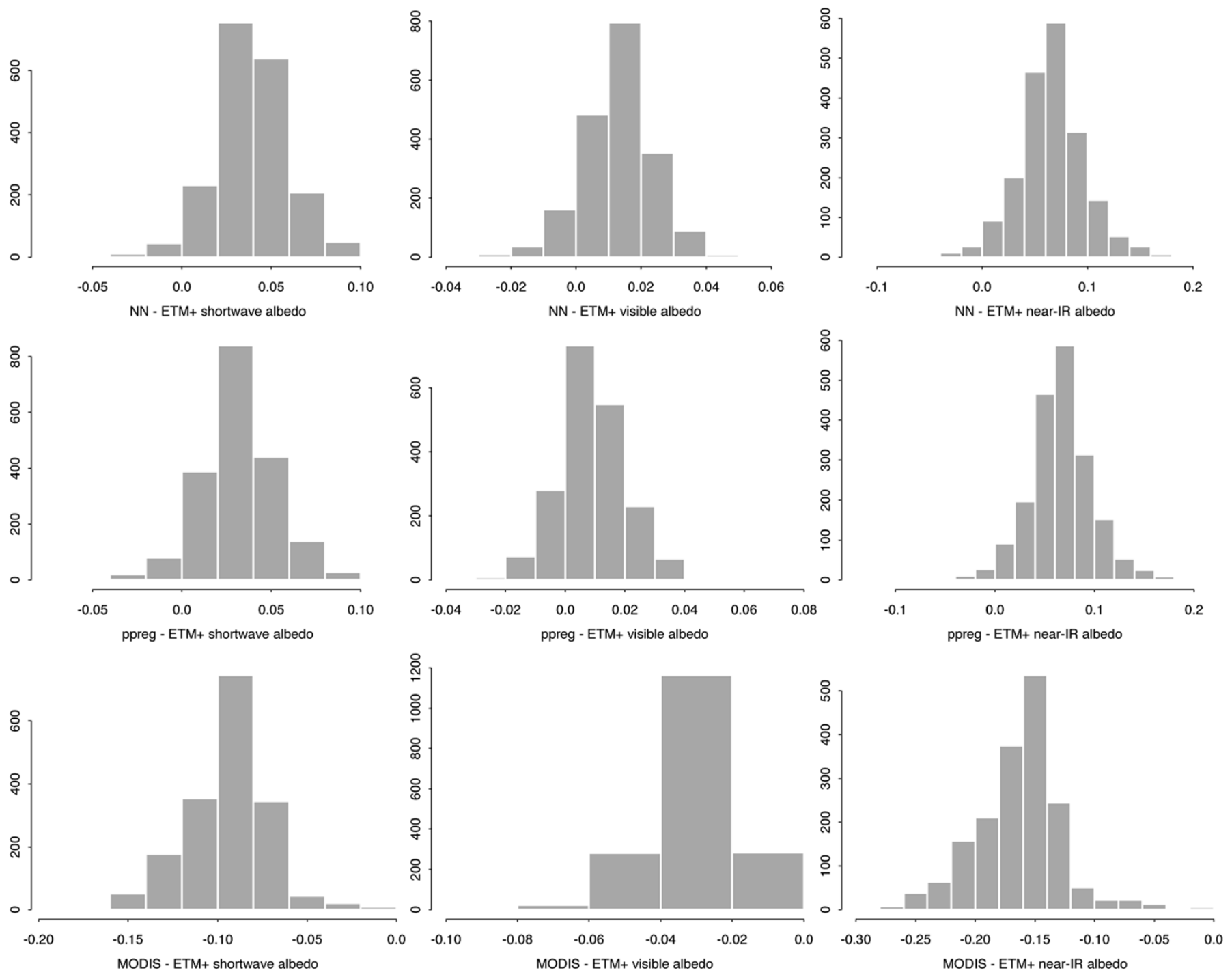

Fig. 6. Same as Fig. 4 except both ETM+ and MODIS were acquired on December 5, 2000.

2) Projection Pursuit Regression: Projection pursuit regression [24] applies an additive model to projected variables

$$
\alpha=\sum_{i=1}^{M} f_{i}\left(w_{k}^{T} R\right)+\varepsilon
$$

where $R=\left(R_{1}, R_{2}, \ldots, R_{n}\right)$ is the explanatory vector (i.e., spectral reflectance in this particular case). It can be further expressed as

$$
\alpha=w_{0}+\sum_{i=1}^{M} f_{i}\left(w_{k}^{T} R\right)
$$

The "projection" part of the term "projection pursuit regression" indicates that the carrier vector $\mathbf{R}$ is projected onto the direction vectors $w_{1}, w_{2}, \ldots, w_{M}$, and the "pursuit" part indicates that an optimization technique is used to find "good" direction vectors $w_{1}, w_{2}, \ldots, w_{M}$. For any applications, the important parameter to be determined is $M$. It depends on the number of variables and the amount of training data. There are some general guidelines to determine its value in $S$-plus, but it is found in this study that the results are not very sensitive when its value is set from $15-25$.

\section{CASE STUdies}

Several case studies were conducted in this study to evaluate if this approach is reasonably accurate in estimating land surface broadband albedos from MODIS imagery. The first case is based on several clear images over the greater Washington, DC area where ground measurements were scaled up through Landsat7 ETM+ imagery. The second case demonstrates how this method can retrieve surface broadband albedos by automatically removing a large thick patch of aerosols.

\section{A. Case 1: Greater Washington, DC Area}

The first experiment was conducted using MODIS imagery of the greater Washington, DC region acquired on May 11, 2000, November 3, 2000, December 5, 2000, and January 22, 2001, shown in Fig. 2(a)-(d), respectively. These images contains a NASA EOS Land Core Validation Site at the U.S. Department of Agriculture (USDA) Agricultural Research Service Beltsville 

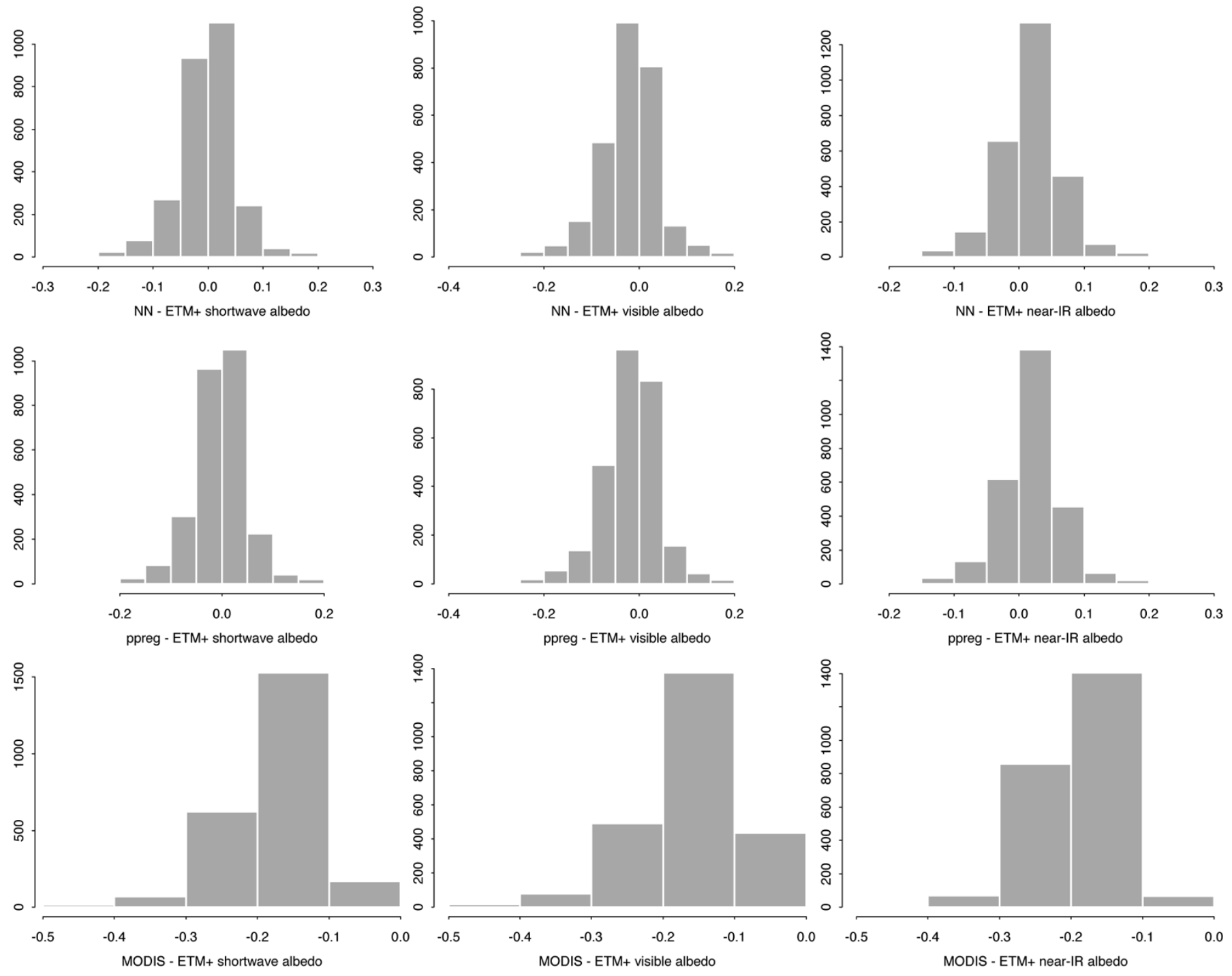

Fig. 7. Same as Fig. 4 except both ETM+ and MODIS were acquired on January 22, 2001.

Agricultural Research Center (BARC), in Beltsville, MD. This site is located at the northeast of Washington, DC including the NASA Goddard Space Flight Center (GSFC). On May 11, 2000, there was an extensive field campaign with several aircraft missions and ground measurements. The sunphotometer located at GSFC as part of AERONET [25] measured aerosol optical depth and water vapor content of the atmosphere continuously.

For all dates, there are clear Landsat7 ETM+ images (see Fig. 3), acquired about 45 min earlier than MODIS. ETM+ imagery were corrected atmospherically using MODTRAN with inputs from sunphotometer measurements. Some of the retrieved surface reflectance were calibrated using ground radiometric measurements. The retrieved surface spectral reflectance were converted to the broadband albedos using the linear conversion formulae [7] that were later well validated [26]. These high-resolution albedo products were then aggregated into MODIS resolution $(1 \mathrm{~km})$ using a two-step registration process. This procedure is used to validate the MODIS directional reflectance and albedo products [27].

The histograms of three broadband albedo differences between ETM+ and those produced by both the NN and the projection pursuit regression procedure on May 11, 2001 are shown in Fig. 4. The mean and standard deviation of the difference between neural network (nnet)/projection pursuit regression (ppreg) are listed in Table II. Note that the predicted albedos from both $\mathrm{NN}$ and projection pursuit regression are always larger than that from ETM+. These differences may come from many different sources, such as the assumption of a Lambertian surface, image registration, and choice of aerosol model. The MODIS albedo products on May 11, 2000 were not available at this point.

The same histograms on November 3, December 5, 2000, and January 22, 2001 are shown in Figs. 5-7. The mean and standard deviation of albedo difference between neural network (nnet)/projection pursuit regression (ppreg) are also listed in Table II. Note that we have also compared these with the MODIS albedo products generated by the MODIS science team. From Figs. 5-7, we can see that our new approach using both NN and projection pursuit regression can consistently produce results similar to the predicted broadband albedos from ETM+ imagery. On November 3 (Fig. 5) all products look very similar. However, on both December 5, 2000 and 
January 22, 2001, the MODIS products are quite different from ETM+ albedos and our new albedo products. Overall, MODIS albedos are much smaller. This may be partially due to the fact that MODIS albedos are the average values over the period of 16 days, while ETM+ and our new albedo values are the instantaneous ones. It is also possibly largely the result of inaccurate MODIS atmospheric correction. The MODIS albedo products are significantly smaller on January 22 when the surface was covered by snow. We also converted MISR spectral albedos to three broadband albedos on January 22, and the results are very close to both ETM+ albedos and our new albedos using this new procedure. The detailed comparisons with MISR products will be presented elsewhere.

In all these cases, MODIS atmospheric correction certainly introduces errors and affects the accuracy of the broadband albedo products, since it relies on large areas of dense green vegetation that are very difficult to find in this area in the winter season.

Overall, the average albedo differences and the standard deviations from ETM+ albedos are 0.026 and 0.023 (shortwave), 0.009 and 0.017 (visible), and 0.035 and 0.036 (near-IR) for the NN. For the projection pursuit regression method, the corresponding values are 0.009 and 0.035 (shortwave), 0.004 and 0.035 (visible), and 0.025 and 0.041 (near-IR).

\section{B. Case 2: Northeastern Coast, China}

This case study is to apply this new method to a MODIS image of the northeastern coast of China acquired on May 7 , 2000. The true-color composite image (bands 1, 3, and 4) of $400 \times 400$ pixels is displayed in Fig. 8. The spatial resolution is $1 \mathrm{~km}$. This image is severely contaminated by heterogeneously distributed aerosol particles. Land cover types include snow, ocean water, dense vegetation, and others. It is obvious that the TOA albedos are quite different from surface albedos. We do not have any "ground truths" in this area and did not attempt to collect high-resolution imagery, such as an ETM+ image. Based on the first case study, we feel confident that our new method can predict the land surface albedos accurately. The major objective in this case study is to demonstrate how this new method can remove the observed haze effect.

The MODIS level 1 data were converted to TOA reflectance. The broadband albedo predicted using the NN method are shown in Fig. 8. It is clear that most haze has been effectively removed, although some very thick parts still remain in the visible albedo map. The visible albedo of snow cover at the left corner seems lower, which leads us to speculate that the snow might be very old and contaminated by vegetation and other pollutants. The projection pursuit regression method produced very similar results. The differences of the three broadband albedos are displayed in Fig. 9.

In this experiment, we used the rural aerosol model, one of the MODTRAN default models. It is found that different aerosol models can cause large impacts on atmospheric radiative quantities. We believe this might be one of the major sources of uncertainty. In fact, this is the generic problem in any atmospheric correction using the radiative transfer model. MISR or other sensors can provide more accurate aerosol climatology models.

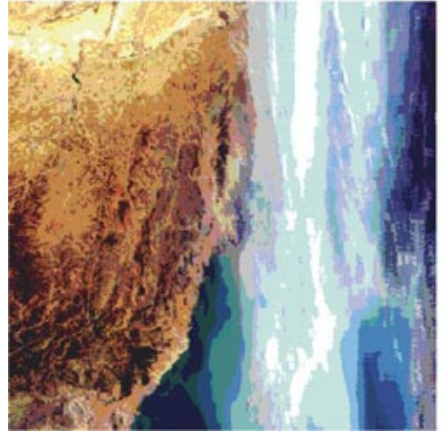

(a)

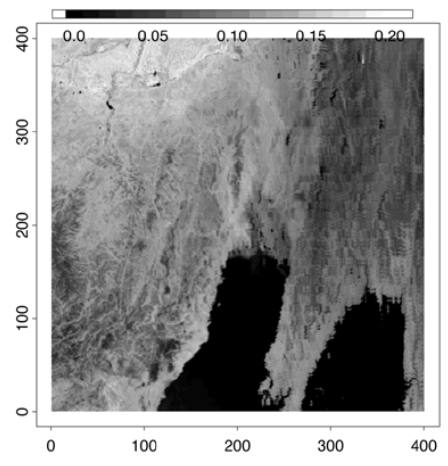

(c)

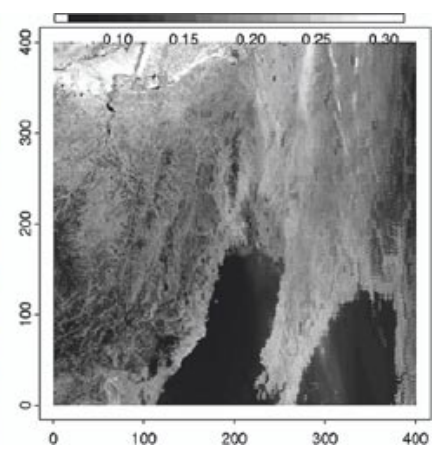

(b)

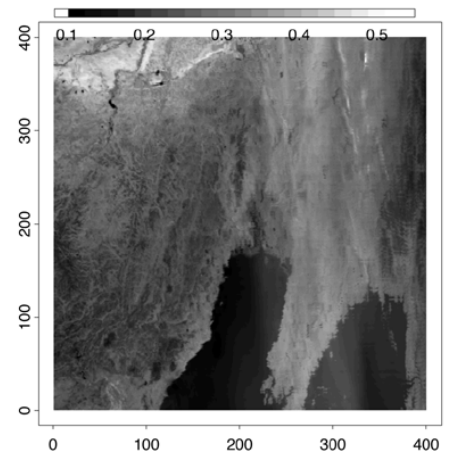

(d)
Fig. 8. (a) Color composite MODIS level 1 image acquired on May 7, 2000 over northeastern China and the retrieved land surface three broadband albedo maps using the NN method: (b) total shortwave, (c) total visible, and (d) total near-IR.

\section{Discussion AND CONCLUSION}

Land surface broadband albedo is a fundamental component in modeling any surface processes. The current common estimation approach from multispectral satellite observations is composed of a series of processing steps, typically including atmospheric correction for estimating land surface directional reflectance, angular modeling for calculating spectral albedos, and narrowband-to-broadband albedo conversions. Each step may have errors that ultimately impact the accuracy of the final broadband albedo products. For example, the current operational atmospheric correction algorithms usually rely on the "dark-object" methods for estimating aerosol optical depth for densely vegetated regions. They fail over nonvegetated regions, such as snow, ice, and bare soils, which usually have much larger albedo values. For multispectral sensors that have one viewing direction at a time, observations have to be accumulated during a period of time (i.e., 16 days for MODIS) to determine the parameters of the angular model. The derived albedo products, therefore, represent the average state for that period of time. If the atmospheric condition or surface conditions change dramatically, larger uncertainty will be introduced. If the number of spectral bands is not large, the conversions from narrowband to broadband albedos also introduce errors.

In this study, our alternative broadband albedo estimation method [10] has been greatly improved using actual MODIS imagery. This new method does not need all the processing steps mentioned above, and it links TOA reflectance with land surface broadband albedos directly. It is actually a hybrid method that 


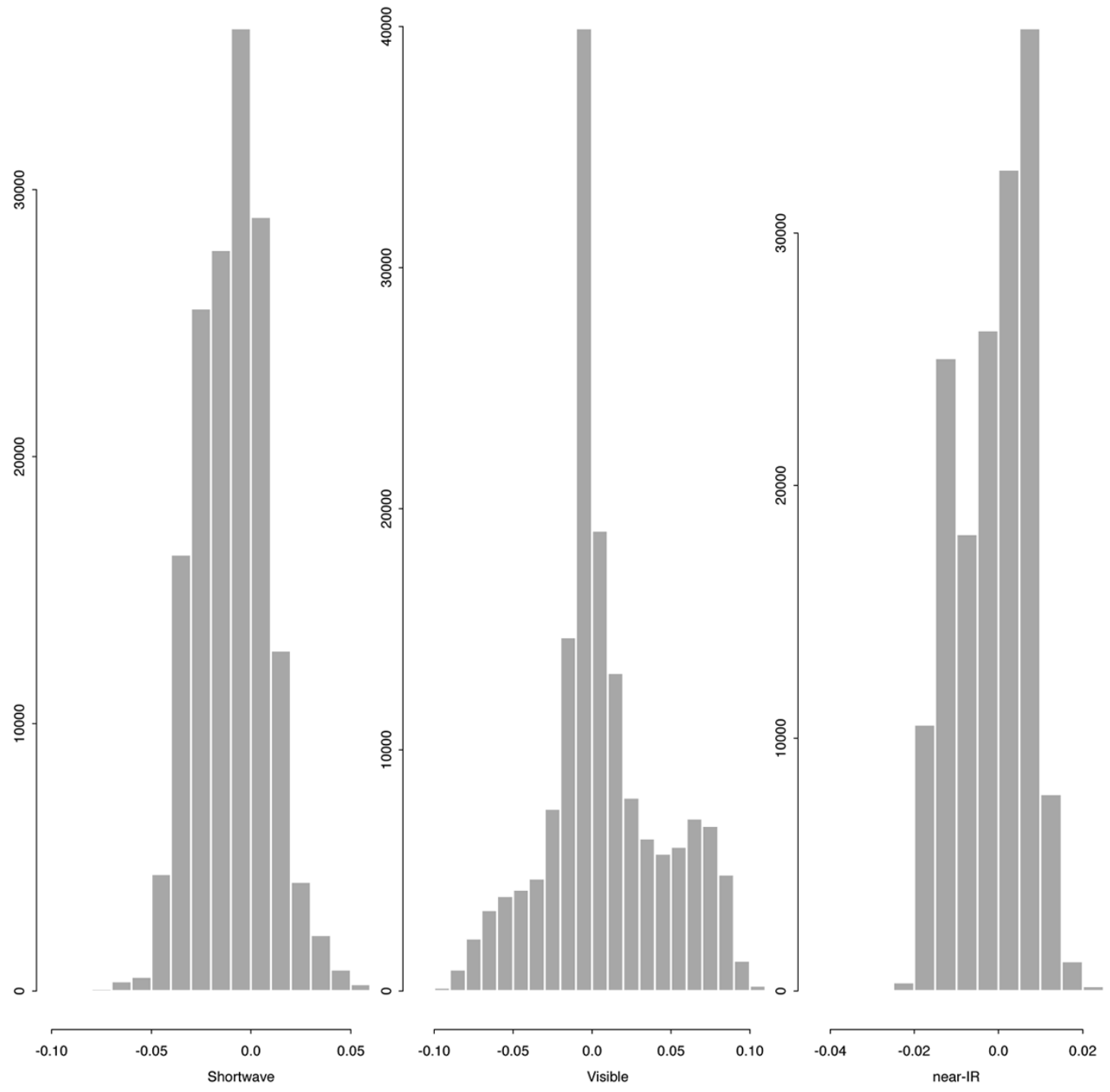

Fig. 9. Histograms of the albedo differences predicted from both $\mathrm{NN}$ and prejection pursuit regression methods from the same images as Fig. 8.

combines the extensive radiative transfer simulations (physical) and nonparametric regression algorithms (statistical).

Two case studies are presented in this paper. The first one validates the accuracy of this method using ground measurements and high-resolution imagery over our test site at Beltsville, Maryland. The ground measurements were used to calibrate the high-resolution albedo products from Landsat ETM+ imagery. The high-resolution albedo products were then aggregated to register with MODIS imagery. Data from four dates (May 11, November 3, December 5, 2000, and January 22, 2001) demonstrated that this new method is reasonably accurate. Both NN and projection pursuit regression produced consistently similar results. The average mean albedo differences from ETM+ albedos are smaller than 0.03 (shortwave), 0.01 (visible), and 0.04 (near-IR), and the standard deviations are smaller than 0.04 . These numbers are good indications of the accuracy of this new method. The MODIS black-sky albedos products were also used in the comparisons. The results indicate that our new method produces albedo with accuracy comparable to the MODIS standard albedo products and is even better when the surface conditions are highly variable (e.g., snow).
The second case demonstrated that this new method can recover land surface broadband albedos from the heavily contaminated MODIS image of northeastern China by aerosol particles without performing any atmospheric correction.

In this paper, a Lambertian surface has been assumed in the MODTRAN radiative transfer simulation as a first-order approximation. But it is not an inherent limitation of this new algorithm. The reasons for making such an assumption is that it not only significantly simplifies the procedure but also results from the fact that a global surface BRDF database at the 1-km scale is simply not available at this point. As long as we continue to gain a deeper understanding of the surface non-Lambertian properties and accumulate enough data from MODIS [3], [4], MISR [19], [28], or other sensors, incorporating a non-Lambertian surface into the radiative transfer simulation is straightforward. MODTRAN already has such an option. On the other hand, our case studies have proven that this approximation does not affect the inversion accuracy significantly. The error associated with this approximation is intuitively expected to be much smaller than those due to the failed atmospheric correction over nonvegetated surfaces or the use of a wrong BRDF model during 
a period of 16 days when a sudden change of the surface conditions affects the current MODIS algorithm.

The implementation of this method for global operational applications is straightforward. The major changes will be the use of more realistic climatology aerosol models that are being produced by the MISR teams rather than the MODTRAN default aerosol models and more surface reflectance spectra. This new method is particularly promising for nonvegetated land surfaces, such as snow, ice, desert, and high-altitude land masses at winter nongrowing season.

\section{ACKNOWLEDGMENT}

The author likes to thank the MODTRAN development team for making their code available to us, the ASTER science team for providing the ASTER Spectral Library data, C. Schaaf, F. Gao, and A. Strahler in the MODIS science team for providing us with the MODIS data products and valuable extensive discussions, H. Fang and M. Chen for their great assistance in processing MODIS data, and finally the anonymous reviewers for their valuable comments that have greatly improved the presentation of this paper.

\section{REFERENCES}

[1] D. L. Hartmann, C. S. Bretherrton, T. P. Charlock, M. D. Chou, A. Del Genio, R. E. Dickinson, R. Fu, R. A. Houze, M. D. King, K. M. Lau, C. B. Leovy, S. Sorooshian, J. Washburne, B. Wielicki, and R. C. Willson, "Radiation, clouds, water vapor, precipitation, and atmospheric circulation," in EOS Science Plan. Greenbelt, MD: NASA, 1999, pp. 39-114. Available [Online]: http://eospso.gsfc.nasa.gov/science_plan/index.php.

[2] S. Liang, J. Stroeve, I. Grant, A. Strahler, and J. Duvel, "Angular corrections to satellite data for estimating earth radiation budget," Remote Sens. Rev, vol. 18, pp. 103-136, 2000.

[3] W. Lucht, C. B. Schaaf, and A. H. Strahler, "An algorithm for the retrieval of albedo from space using semiempirical BRDF models," IEEE Trans. Geosci. Remote Sensing, vol. 38, pp. 977-998, Mar. 2000.

[4] C. Schaaf, A. Strahler, W. Lucht, T. Tsung, F. Gao, X. Li, N. Strugll, L. Chen, P. Muller, P. Lewis, M. Barnsley, P. Hobson, M. Disney, M. Dunderdale, R. d'Entremont, B. Hu, S. Liang, J. J. Privette, and D. Roy, "First operational BRDF, albedo, nadir reflectance products from MODIS," Remote Sens. Environ., vol. 83, pp. 135-148, 2002.

[5] E. Vermote, N. El Saleous, C. Justice, Y. Kaufman, J. Privette, L. Remer, J. Roger, and D. Tanre, "Atmospheric correction of visible to middleinfrared EOS-MODIS data over land surfaces: Background, operational algorithm and validation," J. Geophys. Res., vol. 102, pp. 17 131-17 142, 1997.

[6] W. Lucht and J. L. Roujean, "Considerations in the parametric modeling of BRDF and albedo from multiangular satellite sensor observations," Remote Sens. Rev., vol. 18, pp. 343-380, 2000.

[7] S. Liang, "Narrowband to broadband conversions of land surface albedo," Remote Sens. Environ., vol. 76, pp. 213-238, 2001.

[8] Y. J. Kaufman, A. Wald, L. A. Lorraine, B. C. Gao, R. R. Li, and L. Flynn, "Remote sensing of aerosol over the continents with the aid of a $2.2 \mu \mathrm{m}$ channel," IEEE Trans. Geosci. Remote Sensing, vol. 35, pp. 1286-1298, Sept. 1997.

[9] S. Liang, H. Fallah-Adl, S. Kalluri, J. JaJa, Y. J. Kaufman, and J. R. G. Townshend, "An operational atmospheric correction algorithm for Landsat Thematic Mapper imagery over the land," J. Geophys. Res., vol. 102, pp. $17173-17186,1997$.

[10] S. Liang, A. Strahler, and C. Walthall, "Retrieval of land surface albedo from satellite observations: A simulation study," J. Appl. Meteorol., vol. 38, pp. 712-725, 1999.

[11] T. Chen and G. Ohring, "On the relationship between clear-sky planetary and surface albedos," J. Atmos. Sci., vol. 41, pp. 156-158, 1984.

[12] R. T. Pinker, "Determination of surface albedo from satellite," $A d v$ Space Res., vol. 5, pp. 333-343, 1985.
[13] P. Koepke and K. T. Kriebel, "Improvements in the shortwave cloud-free radiation budget accuracy, Part I: Numerical study including surface anisotropy," J. Clim. Appl. Meteorol., vol. 26, pp. 374-395, 1987.

[14] Z. Li and L. Garand, "Estimation of surface albedo from space: A parameterization for global application," J. Geophys. Res., vol. 99, pp. 8335-8350, 1994.

[15] A. Berk, L. S. Bernstein, G. P. Anderson, P. K. Acharya, D. C. Robertson, J. H. Chetwynd, and S. M. Adler-Golden, "MODTRAN cloud and multiple scattering upgrades with application to AVIRIS," Remote Sens. Environ., vol. 65, pp. 367-375, 1998.

[16] E. Vermote, D. Tanre, J. L. Deuze, M. Herman, and J. J. Morcrette, "Second simulation of the satellite signal in the solar spectrum: An overview," IEEE Trans. Geosci. Remote Sensing, vol. 35, pp. 675-686, May 1997.

[17] P. Ricchiazzi, S. Yang, C. Gautier, and D. Sowle, "SBDART: A research and teaching software tool for plane-parallel radiative transfer in the earth's atmosphere," Bull. Amer. Meteorol. Soc., vol. 79, pp. 2101-2114, 1998.

[18] K. N. Liou, An Introduction to Atmospheric Radiation. New York: Academic, 1980.

[19] D. Diner et al., "Multi-angle Imaging SpectroRadiometer (MISR) instrument description and experiment overview," IEEE Trans. Geosci. Remote Sensing, vol. 36, pp. 1072-1097, July 1998.

[20] D. Kimes, R. Nelson, M. Manry, and A. A. Fung, "Attributes of neural networks for extracting continuous vegetation variables from optical and radar measurements," Int. J. Remote Sens., vol. 19, pp. 2639-2663, 1998.

[21] S. Gopal and C. Woodcock, "Remote sensing of forest change using artificial neural networks," IEEE Trans. Geosci. Remote Sensing, vol. 34, pp. 398-404, Mar. 1996.

[22] W. N. Venables and B. D. Ripley, Modern Applied Statistics With S-Plus. New York: Springer-Verlag, 1994.

[23] B. D. Ripley, "Neural networks and flexible regression and discrimination," Adv. Appl. Stat., vol. 2, pp. 39-57, 1994.

[24] J. Friedman and W. Stuetzle, "Projection-pursuit regression," J. Amer. Stat. Assoc., vol. 76, pp. 183-192, 1981.

[25] B. N. Holben, T. Eck, I. Slutsker, T. Tanre, J. Buis, A. Setzer, E. Vermote, J. Reagan, Y. Kaufman, T. Nakajima, F. Lavenu, I. Jankowiak, and A. Smirnov, "AERONET-A federated instrument network and data archive for aerosol characterization," Remote Sens. Environ., vol. 66, pp. 1-16, 1998.

[26] S. Liang, C. Shuey, H. Fang, A. Russ, C. Walthall, and C. Daughtry, "Narrowband to broadband conversions of land surface albedo: II. Validation," Remote Sens. Environ., vol. 84, no. 1, pp. 25-41, 2003.

[27] S. Liang, H. Fang, M. Chen, C. Shuey, C. Walthall, C. Daughtry, J. Morisette, C. Schaaf, and A. Strahler, "Validating modis land surface reflectance and albedo products: Methods and preliminary results," Remote Sens. Environ., vol. 83, pp. 149-162, 2002.

[28] J. V. Martonchik, D. J. Diner, R. A. Kahn, T. P. Ackerman, M. E. Verstraete, B. Pinty, and H. R. Gordon, "Techniques for the retrieval of aerosol properties over land and ocean using multiangle imaging," IEEE Trans. Geosci. Remote Sensing, vol. 36, pp. 1212-1227, July 1998.

[29] S. Liang, Quantitative Remote Sensing of Land Surfaces. New York: Wiley, 2003, to be published.

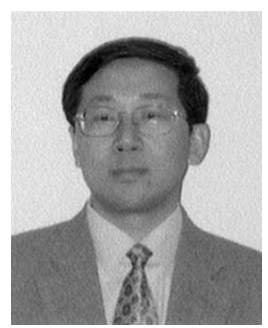

Shunlin Liang (M'94-SM'00) received the Ph.D. degree in remote sensing and GIS from Boston University, Boston, MA.

He was a Postdoctoral Research Associate at Boston University from 1992 to 1993, and Validation Scientist of the NOAA/NASA Pathfinder AVHRR Land Project from 1993 to 1994 . He is currently an Associate Professor at the University of Maryland, College Park. His present research interests focus on land surface data assimilation, parameter retrieval from remotely sensed data, and spatial analysis.

Dr. Liang organized the International Forum on BRDF at San Francisco, CA, in December 1998, and coedited a special issue of the Remote Sensing Reviews. $\mathrm{He}$ has chaired various sessions of the international conferences and served as the chairman of the IEEE Geosciences and Remote Sensing Society, Washington/North Virginia Chapter (2000). He is an Associate Editor of the IEEE TRANSACTIONS ON GEOSCIENCE AND REMOTE SENSING. 